\title{
Evaluating Experiential Learning Approaches for Asian Students at North American Universities
}

\author{
Chen-Yu (Crystal) Feng ${ }^{1}$, Wei Song ${ }^{2}$, David D. Schein ${ }^{3} \&$ Paul Clark $^{4}$ \\ ${ }^{1}$ School of Management, Tianjin University of Technology, Tianjin, China \\ ${ }^{2}$ School of Business, Black Hills State University, USA \\ ${ }^{3}$ Cameron School of Business, University of St. Thomas, TX, USA \\ ${ }^{4}$ School of Business and Economics, Thompson Rivers University, BC, Canada \\ Correspondence: Wei Song, School of Business, Black Hills State University, 1200 University Street, Spearfish, \\ South Dakota, 57783, USA. Tel: 605-642-6867. E-mail: wei.song@bhsu.edu
}

\author{
Received: May 15, $2021 \quad$ Accepted: June 28, $2021 \quad$ Online Published: September 8, 2021 \\ doi:10.5539/ies.v14n10p14 URL: https://doi.org/10.5539/ies.v14n10p14
}

\begin{abstract}
In recent years, experiential learning modality has become an integral part of business education in international programs. Although extensive research has been conducted in the experimental learning arena, the research regarding international students, especially the rapidly growing number of Asian students, with a significant percentage from China, is still limited. This study utilized a mixed-methods design using Kolb Experiential Learning Theory (ELT) to investigate the preferred experiential learning (EL) pedagogical practices for Asian students while studying at North American universities. This study revealed that students with a positive attitude toward EL could fundamentally strengthen their learning outcomes. In contrast, well-balanced learning styles should be emphasized instead of ranking the priority of learning preferences or taking only one learning approach. The limitations of the study and the future direction of related research are also presented.
\end{abstract}

Keywords: Kolb Experiential Learning Theory, experiential learning, pedagogical practices, learning styles, North American university, Asian students

\section{Introduction}

Since the 1990s, significant international students have pursued their studies in business and management in Western countries (Levsen, Goettel, Chong, \& Farris, 2001). Based on the statistics from the Canadian Bureau for International Education (CBIE) (2018) and the Migration Policy Institute's Spotlight: International Students in the United States (Zong \& Batalova, 2018), international students in North America reached a total of 1,522,730 during the 2016-2017 school year. The total number of Asian students in the US and Canada in that period was 972,660.00, which is about $64 \%$ of international students in North America. Among them, there were 491,530 Chinese students, which comprised 33\% of the international students in both US and Canada combined in 2017. With the increase in the diversity of the student population in North America, universities must identify preferred teaching practices within the context of this substantial diversity in the student population.

Due to its effectiveness, many business schools have started incorporating EL in their pedagogy (Piercy \& Caldwell, 2011; Schelbe, Petracchi, \& Weaver, 2014; Schenck \& Cruickshank, 2015; Schein \& Song, 2016; Seaman, Brown, \& Quay, 2017). In addition, the Association to Advance Collegiate Schools of Business (AACSB) encourages its member business schools to adopt experiential learning activities (https://www.aacsb.edu/about).

Experiential education pedagogy is increasingly practiced in Western business schools. In contrast, most Asian countries practice a passive learning style that involves teachers leading the class. At the same time, students follow their teachers' instructions. Thus, there is a clear separation between the teacher and the students (Chen, 2014). To better suit the needs of international students, universities have an opportunity to seek and identify appropriate pedagogies for their business school offerings (Okoli, Nuno, \& Barish, 2019).

Although EL has been extensively studied in business education, current literature has mainly focused on Western student populations. There is minimal research on Non-Western students, especially of Asian student groups 
studying in North America. More studies of the diverse international student populations are needed (Azriel et al., 2005; Piercy and Caldwell, 2011).

Asian students studying in North America can be broadly divided into Short-term exchange program students and Long-term degree-seeking students. Due to the difference in the study duration, a "one size fits all" approach may not be appropriate when developing preferred EL practices for these different groups of Asian students. However, both groups are used to the passive learning style, i.e., following instructions precisely provided by their instructors, which is the standardized approach in most Asian universities, especially Chinese universities. Of course, some similarities do exist. Therefore, this study takes two routes: develop general EL approaches for both groups of Asian students while offering alternatives with specific strategies for each group. Furthermore, many studies have asserted that a positive attitude toward the pedagogy in use could be a success factor in ensuring high-quality learning outcomes (Getie, 2020). Therefore, students' positive attitudes toward EL are crucial to the successful use of EL for Asian students studying in North American universities.

Using a mixed research method to explore the preferred EL method for Asian students, with the majority from China and the Far East, two research questions were developed:

1) What are the attitudes of Asian students toward EL?

2) What are the benefits and challenges of adopting EL for Asian students?

This study examined two student groups in a North American university who have participated in EL activities: the Short-term program exchange students, who are at their host school for less than one year; and the Long-term diploma/degree program students, who are at their host school for longer than one year. Both groups share similarities, while it is expected that the Short-term group could be more challenged by this pedagogy due to a shorter period to adjust to an unfamiliar teaching approach.

\section{Literature Review}

Experiential Learning Theory (ELT) has been extensively studied. In the early 1990s, two comprehensive reviews by Hickcox (1991) and Iliff (1994), obtained from both quantitative, 81 studies, and qualitative, 624 studies, indicated that the results of the use of EL were mixed. There were some positive and some neutral reports, and a small group study was even negative. This was even though a significant portion of the studies supported EL pedagogy. In 2016, Burch et al. (2016) conducted a meta-analysis covering over 40 years of research studies which systematically reviewed 5,513 articles, including 832 empirical studies. The authors comprehensively examined the relationship between EL and learning outcomes based on 53 empirical studies out of these 832 papers. The research concludes that EL pedagogy enables students to achieve a superior learning outcome (Burch et al., 2016).

ELT is the collection of educational scholars' work, such as John Dewey, Kurt Lewin, and Jean Piaget, among others (Kolb, D.A. 1984). ELT defines learning as the process of obtaining knowledge through experience (Kolb, A.Y. 2005). Based on Kolb's ELT, there are two routes of response to learning: Concrete Experience (CE) and Abstract Conceptualization (AC). This is paired with two ways of transforming the experience into knowledge: Reflective Observation (RO) and Active Experimentation (AE). The former is called the perception continuum, while the latter is considered the performing continuum. ELT proposes this learning process cycle: (1) concrete experience; (2) observation and reflection; (3) forming abstract concepts; (4) and testing in new situations (Kolb, D.A.). The learning cycle describes how immediate concrete experiences (CE) serve as the basis for observation and reflection (RO), in which the experience is subsequently assimilated into abstract conceptualization (AC). Moreover, from $\mathrm{AC}$, the experience is then formed into active experimentation (AE) with the world. Thus, $\mathrm{AE}$ both completes the learning cycle and ensures that it begins a new cycle by creating new experiences (Kolb, D.A.).

Kolb's four-step process has subsequently been widely accepted as a holistic approach involving affect, perception, cognition, and behavior (Kolb, 1984). These experiential learning cycles are also the foundation of experiential learning styles. Four types of learning styles have been identified by Kolb (1984): Divergent, Assimilative, Convergent, and Accommodative. The Divergent learning style stresses CE and RO. The Assimilative learning style focuses on AC and RO. The Convergent learning style emphasizes AC and AE. Finally, the Accommodative learning style identifies with $\mathrm{CE}$ and AE. Ultimately, understanding the international students learning style preferences enables the institutions to have better EL practices.

Students' positive attitudes toward the learning styles/pedagogies play a significant role in their success. Many scholars have confirmed that students' attitudes are a critical component of the learning process (Getie, 2020). Therefore, students' positive attitudes toward Kolb's experiential learning styles could ensure and accelerate the 
adoption of experiential learning pedagogy.

Although Kolb's ELT model has been well received, some critics exist. For instance, critics argue that the model lacks reflective analyses and does not address the impact of emotions, which could interfere in students' deep learning process (Vince, 1998; Miller \& Maellaro, 2016; Matsuo \& Nagata, 2020). However, like any other pedagogies, experimental learning methods have weaknesses. Moreover, an experiential learning approach is just one of the learning modalities utilized in a college business school. Furthermore, when combined with other learning methods, such weaknesses could be lessened.

\section{Methodology}

This study explores pedagogical ways to improve international students' perception of and performance in the EL process, focusing on Asian students. This is accomplished by identifying the perceptions of international students and the preferred EL pedagogical practices.

Owing to the intricacy of the research topic and the uniqueness of the student population, the authors have adopted a mixed research methods design, with more weight on the qualitative research outcomes. This design permits the researchers to use different data collection forms to confirm or discount the results generated based on data comparisons (Creswell, 2014).

Data for this survey is drawn from three different sources. One source of data is Asian students studying at a public university in British Colombia, Canada. This homogeneous purposive sample included 112 students who were engaged to complete a questionnaire. The second data source is drawn from a sub-group of 26 students out of the 112 students selected to participate in additional individual interviews. The third source of data is extracted from four Asian students from a regional university in the United States and six students from a provincial university in China who were interviewed individually. These students provided additional responses regarding the use of EL pedagogy.

The participants from both research streams, quantitative and qualitative, had the following characteristics, which were considered relevant for this study:

- International students

- Business majors

- Studying in Canada or the USA for a few months to a few years

- English is their second language

- All were exposed to EL activities

- The primary teaching method in their home countries was lecture-based pedagogy.

Survey and interview data were collected at the same time but analyzed independently. Then, the data were analyzed to build the results matrix, including quantitative variables and qualitative themes.

The survey data were analyzed using the descriptive statistics method to address international students' perceptions regarding EL. In addition, two statistical measurements were performed: the measure of central tendency and the measure of variability.

Interview data were drawn from Asian students. First, the data reduction was performed to address why and how EL impacted the surveyed students. Then, data coding was performed using an inductive coding approach. In turn, "open coding" was used through some pre-coded themes based on the literature.

In addition, teaching notes, observation notes, and EL activities design papers were reviewed for supplemental information.

\subsection{Quantitative Method}

The quantitative part of the study included a total of 112 international students in the survey. For this study, international students are defined as those who chose to undertake all or part of their tertiary education in a country other than their own and move to that country for their studies. These students were divided into two groups: Group A, Short-term, and Group B, Long-term. Short-term students had studied less than one year, while Long-term students had studied more than one year at the selected university.

Most students from the Short-term group in the survey are from Asian countries, with the majority from China. In the Long-term group, there was a mix of Asian and non-Asian international students. One week after the end of the semester, the survey was distributed to these students, including the Short-term group of 43 students and the Long-term group of 69 students. 
The students in the Short-term group were also exposed to EL methods through their respective courses, such as consumer behavior, entrepreneurship, and principles of marketing classes. These activities were related to the projects for local businesses and organizations. Also, the standard English test was not required for this group because the students had a good command of English skills utilizing training from their home countries.

Among the students in the Long-term group, 23 students had taken a service-learning course as a first-year, credit-bearing elective. To register for the service-learning course, all these students must have been placed at level four or higher in the English as a second language course. Level four requires an English proficiency score of at least 5.5 on IELT or 71 on the TOEFL. Although this group of students met in class for three hours each week for the entire 12-week semester, they also spent a minimum of twenty-four hours serving at a local non-profit organization.

The remaining 46 students took the course as a third-year, credit-bearing course. The professor adopted EL methods through project-based activities in one of the authors' international business classes. In the class, a group with four to five students finished their projects as a part of EL activities.

The survey questions are grouped into three parts, and each part includes five items, each rated on a 5-point Likert scale. It was administered to the international students. The survey questions addressed the following for the undergraduate students: First, their attitude toward EL based on ELT; second, the benefits and challenges they have faced in EL based on their participation in the activities.

A survey of 112 responses was obtained, as shown in Table 1.

Table 1. Demographics of the student population

\begin{tabular}{lc}
\hline $\mathrm{N}=112$ & Frequencies \\
\hline Gender & \\
\hline Male & 49 \\
Female & 63 \\
\hline Years of studying abroad & 43 \\
\hline Less than one year & 23 \\
Between 1-2years & 46 \\
\hline Above 2year & \\
\hline Ethnic Origin & 62 \\
\hline Asían (China, Jipan, Korea India) & 50 \\
\hline
\end{tabular}

\subsection{Qualitative Method}

The qualitative method employed was the semi-structured group and individual interviews to analyze the students' attitude toward experiential learning and their perception of learning experiences in their home country compared with their host country experiences. A total of 36 students were interviewed. This included twenty-six in Canada, four in the USA, and six in China.

A focus group with seven students was also conducted to obtain the questions for developing the survey questionnaire. In addition, to reduce the possibility of the "group-think" problem, the participants did not know each other well. They were also asked to rank the questions based on the priorities of their opinions. These steps were designed to reduce the group-think influence.

The questions in the semi-structured group and individual interviews are as follows: 1 . What are your responses to EL; 2. What are the main benefits of participating in EL activities and why; 3. What are the main challenges during the EL activities and why; 4 . What are your preferred teaching methods; and 5. What are your suggestions to overcome the challenges you have encountered during your EL activities? The first three questions are the same as in the survey questionnaire. The last two questions were additions that were not used in the questionnaire.

One significant difference between surveys and interviews is that there are close-end questions in surveys, while open-ended questions are used in the interviews. Probing and follow-up questions can also be employed during interviews. The member-checking procedure was performed to secure the accuracy of the data. 


\section{Research Findings and Data Interpretation}

The findings of this research are divided into two sections. Section I: the analysis of the survey results and Section II: the analysis of the interview results.

\subsection{The Analysis of the Survey Results}

The three parts of the survey with 15 questions were designed to examine international students' perceptions regarding their attitudes, perceived benefits, and challenges related to EL. The responses are shown in Table 2.

Table 2. The Results of the questionnaire

\begin{tabular}{|c|c|c|c|c|c|}
\hline \multirow{2}{*}{$\begin{array}{l}\text { Question } \\
\text { Number }\end{array}$} & \multirow[t]{2}{*}{ Classification } & \multicolumn{2}{|c|}{$\begin{array}{c}\text { Rank \& Mean Score, SD for Short-Term } \\
\text { Program }\end{array}$} & \multicolumn{2}{|c|}{$\begin{array}{c}\text { Rank \& Mean Score, SD for Long-Term } \\
\text { Program }\end{array}$} \\
\hline & & $M(S D)$ & Rank & $M(S D)$ & Rank \\
\hline 1 & \multirow{5}{*}{$\begin{array}{l}\text { The attitude toward experiential } \\
\text { learning }\end{array}$} & $3.88(.754)$ & 11 & $3.95(1.129)$ & 14 \\
\hline 2 & & $4.56(.502)$ & 1 & $4.02(.967)$ & 9 \\
\hline 3 & & $3.65(.897)$ & 15 & $4.02(.723)$ & 10 \\
\hline 4 & & $4.23(.718)$ & 5 & $4.03(.884)$ & 8 \\
\hline 5 & & $4.53(.592)$ & 2 & $4.25(.884)$ & 3 \\
\hline 6 & \multirow{5}{*}{$\begin{array}{l}\text { The benefits of experiential } \\
\text { learning }\end{array}$} & $4.44(.734)$ & 3 & $4.16(1.051)$ & 5 \\
\hline 7 & & $4.28(.701)$ & 4 & $4.31(.965)$ & 1 \\
\hline 8 & & $3.81(.824)$ & 12 & $3.75(1.047)$ & 15 \\
\hline 9 & & $3.65(.842)$ & 16 & $4.06(1.134)$ & 7 \\
\hline 10 & & $4.19(.627)$ & 7 & $3.88(1.185)$ & 13 \\
\hline 11 & \multirow{5}{*}{$\begin{array}{l}\text { The challenges of experiential } \\
\text { learning }\end{array}$} & $2.72(1.221)$ & 18 & $3.19(1.301)$ & 18 \\
\hline 12 & & $2.72(.934)$ & 19 & $2.73(1.176)$ & 20 \\
\hline 13 & & $3.81(.958)$ & 13 & $3.37(1.157)$ & 17 \\
\hline 14 & & $2.70(.922)$ & 20 & $2.94(1.014)$ & 20 \\
\hline 15 & & $3.37(.884)$ & 17 & $3.47(1.405)$ & 16 \\
\hline
\end{tabular}

\subsubsection{Students' Attitude toward Experiential Learning Activities}

The responses to Questions 1-5, shown in Table 3 below, were first examined to determine differences between the two groups of international students' attitudes toward EL and closely related to the students' learning style preferences.

Table 3. The comparative mean score and rank of students' attitude toward experiential learning for short-term and long-term participants

\begin{tabular}{|c|c|c|c|c|c|}
\hline \multirow{2}{*}{$\begin{array}{l}\text { Questions } \\
\text { Number }\end{array}$} & \multirow[t]{2}{*}{ Classification } & \multicolumn{2}{|c|}{$\begin{array}{c}\text { Rank \& Mean Score, SD for Short-Term } \\
\text { Program }\end{array}$} & \multicolumn{2}{|c|}{$\begin{array}{c}\text { Rank \& Mean Score, SD for Long-Term } \\
\text { Program }\end{array}$} \\
\hline & & $M(S D)$ & Rank & $M(S D)$ & Rank \\
\hline 1 & \multirow{5}{*}{$\begin{array}{l}\text { The attitude toward experiential } \\
\text { learning }\end{array}$} & $3.88(.754)$ & 11 & $3.95(1.129)$ & 14 \\
\hline 2 & & $4.56(.502)$ & 1 & $4.02(.967)$ & 9 \\
\hline 3 & & $3.65(.897)$ & 15 & $4.02(.723)$ & 10 \\
\hline 4 & & $4.23(.718)$ & 5 & $4.03(.884)$ & 8 \\
\hline 5 & & $4.53(.592)$ & 2 & $4.25(.884)$ & 3 \\
\hline
\end{tabular}

Both groups had a positive attitude toward EL, as indicated in Question 1, Table 3. Their ratings were 3.88 and 3.95. Group B students have a higher standard deviation (1.129), as some students were still adapting to this new learning method.

Additionally, students' attitude according to Kolb's four aspects of the experiential learning process: Concrete Experience (CE), Abstract Conceptualization (AC), Reflective Observation (RO), and Active Experimentation (AE) was also explored. Data results show Group A had similar scores to Group B in responding to learning modes except for AC. Group A had a relatively lower score on AC with a mean score of 3.65 in Question 3, in comparison to the other three dimensions, which were 4.56 in question 2 (CE), 4.23 in question 4 (RO), and 4.53 in question 5 (AE). However, the overall average scores on the attitudes toward EL are very close, with 4.17 in 


\section{Group A and 4.05 in Group B.}

Given the positive academic studies on the success of EL, the researchers expected that the longer the students studied in North America, the stronger their attitude would be toward EL. However, the study does not confirm that anticipated correlation. Thus, the duration of studying overseas may not be the main factor influencing the students' attitudes toward EL. The Short-term group had very similar scores compared with the Long-term group, except for one area linked to Question 3. For Question 3, a lower score from the Short-term group regarding $(\mathrm{AC})$ was a deviation from the other three responses in this set of questions.

It was anticipated that Short-term students would be more influenced by the lecture-based method in their home country. Therefore, Short-term students should score higher on AC than the other three learning methods. The mean score for Question 3 is how they are well-equipped with theories and terminologies or concepts in their academic background to deal with traditional written examinations. Nevertheless, the scores of their attitudes toward AC for the Short-term group were lower than that of the Long-term group. The authors explore some possible reasons for this result from the interviews and will present these reasons in Section II below.

\subsubsection{The Benefits of Experiential Learning:}

Questions 6-10 examined the perceived benefits for international students when adopting EL pedagogy. The results are displayed in Table 4 .

Table 4. The comparative mean score and rank of the benefits in experiential learning between short-term and long-term surveyed students

\begin{tabular}{|c|c|c|c|c|c|}
\hline \multirow{2}{*}{$\begin{array}{l}\text { Questions } \\
\text { Number }\end{array}$} & \multirow[t]{2}{*}{ Classification } & \multicolumn{2}{|c|}{$\begin{array}{c}\text { Rank \& Mean Score, SD for Short-Term } \\
\text { Program }\end{array}$} & \multicolumn{2}{|c|}{$\begin{array}{c}\text { Rank \& Mean Score, SD for Long-Term } \\
\text { Program }\end{array}$} \\
\hline & & $M(S D)$ & Rank & $M(S D)$ & Rank \\
\hline 6 & \multirow{5}{*}{$\begin{array}{l}\text { The benefits of experiential } \\
\text { learning }\end{array}$} & $4.44(.734)$ & 3 & $4.16(1.051)$ & 5 \\
\hline 7 & & $4.28(.701)$ & 4 & $4.31(.965)$ & 1 \\
\hline 8 & & $3.81(.824)$ & 12 & $3.75(1.047)$ & 15 \\
\hline 9 & & $3.65(.842)$ & 16 & $4.06(1.134)$ & 7 \\
\hline 10 & & $4.19(.627)$ & 7 & $3.88(1.185)$ & 13 \\
\hline
\end{tabular}

The research results reveal many similarities between the two groups. For example, the above results from Question 6, which examined if EL is an effective method of learning, showed Group A at 4.44 and Group B at 4.16, which confirms the effectiveness of EL for Asian students for both groups.

The questionnaires have also revealed that a benefit of EL is its ability to facilitate interactions with people in unfamiliar situations. This finding was drawn from Question 7, which inquired about how EL supported exchange with others, backed by data from Question 2, which tested the attitude toward Concrete Experience (CE). Individuals with a strong attitude toward CE may have better people skills. This study indicated both groups benefited from EL as this pedagogy enhanced student interactions, a likelihood of making new friends, and the ability to deal with unfamiliar situations.

Additionally, the data indicate that both groups have a relatively lower score on Question 8 with 3.81 and 3.75, meaning that EL has not helped them realize their unique and effective learning methods. Partially, it may be due to a failure by their faculty to create an appropriate learning space that matches each student's learning style.

The research results also show differences between the two groups. For example, the Long-term group scored higher on applying knowledge, as shown in Question 9. In addition, the group scored 4.06 compared to the Short-term program group, which scored 3.65. These results show that the Long-term group has more well-developed AE styles on the experiential approach, which means the Long-term students may benefit from this stage of the EL cycle.

There are, however, several possible explanations for this discrepancy. One possible answer is that the Long-term group students have become more involved in their host countries and have become more adapted to the foreign culture and different teaching methods. A second explanation may be the goals of the survey subjects. In particular, students in the Short-term group may be focused on finishing their studies in one year or less and returning home. In contrast, the Long-term group may aim to acquire a degree or find a job in the host country. Finally, a third explanation may be that Long-term students were generally involved in richer learning spaces where active experimentation activities took place compared with the Short-term group. 
This research also suggests that some students may be experiencing confusion after one or two years of EL adoption. This is evidenced by data illustrated in Question 10, which asks the subjects if they feel they are learning better. The Short-term group had a score of 4.19, while that of the Long-term group was 3.88. One explanation is that the Short-term group can identify their strengths and weaknesses easier as they are new to this pedagogy. On the other hand, Long-term group students are in the transitional period where somehow they could not clearly define their strengths and weaknesses. For example, the students may previously have thought of some of their shortcomings, but now they believe they have become their strengths.

\subsubsection{The Challenges of Experiential Learning}

Questions 11-15 examined how the international students perceived the challenges of EL, as shown in Table 5.

Table 5. The comparative mean score and rank of the challenges in experiential learning between short-term and long-term survey subjects

\begin{tabular}{|c|c|c|c|c|c|}
\hline \multirow{2}{*}{$\begin{array}{l}\text { Questions } \\
\text { Number }\end{array}$} & \multirow[t]{2}{*}{ Classification } & \multicolumn{2}{|c|}{$\begin{array}{c}\text { Rank \& Mean Score, SD for Short-Term } \\
\text { Program }\end{array}$} & \multicolumn{2}{|c|}{$\begin{array}{c}\text { Rank \& Mean Score, SD for Long-Term } \\
\text { Program }\end{array}$} \\
\hline & & $M(S D)$ & Rank & $M(S D)$ & Rank \\
\hline 11 & \multirow{5}{*}{$\begin{array}{l}\text { The challenges of experiential } \\
\text { learning }\end{array}$} & $2.72(1.221)$ & 18 & $3.19(1.301)$ & 18 \\
\hline 12 & & $2.72(.934)$ & 19 & $2.73(1.176)$ & 20 \\
\hline 13 & & $3.81(.958)$ & 13 & $3.37(1.157)$ & 17 \\
\hline 14 & & $2.70(.922)$ & 20 & $2.94(1.014)$ & 20 \\
\hline 15 & & $3.37(.884)$ & 17 & $3.47(1.405)$ & 16 \\
\hline
\end{tabular}

From their response to Question 11, which asks if students found adapting to EL complex, the students indicated it was not difficult to adjust to the EL pedagogy, even though for most, it was different from their previous academic experiences. In particular, the students from the Short-term group indicated that they found EL less challenging, at 2.72, than the Long-term student group, with a score of 3.19. However, again, this conclusion is counterintuitive, as the study projected that the Short- term group would have more difficulty adapting to EL than the Long-term group.

The research participants were also asked in Question 12 about the range of courses in which EL could be successfully applied. The authors wanted to determine if these students felt that EL was only suitable for "professional courses," such as marketing or entrepreneurship classes. Or, was it also pedagogy applicable to more theoretical courses, such as finance and economics? Of note, both groups of students indicated EL methods could fit both types of classes. However, these students had only taken more "professional" courses with the EL method when the survey was conducted.

The extent that EL may be associated with a heavier and more time-consuming workload compared to a traditional lecture format was also explored in Questions 13 and 15. The results do not show a significant difference between the groups in this area of inquiry. Both groups felt it was manageable to complete EL activities, which was consistent with Question 11. However, Question 15 indicates both groups think EL activities are more time-consuming compared to the lecture-based method.

Question 14 addresses the impact on students of an adequate supportive learning environment outside of the classroom. The answers from both groups are similar as they believe a lack of a favorable external learning environment could be a challenge in adopting EL. Providing a solution to this challenge could come from the institutional, faculty, and local communities.

\subsection{The Analysis of Interview Results}

The qualitative research phase of the study serves two purposes: Making the data comparison to the survey results and gaining a better understanding of international students' insights into adopting EL methods. In addition, the qualitative research focuses on the questions of "why" and "how" about the survey, while the quantitative phase of the study asked "what" had happened.

A total of 36 students were interviewed out of the 112 students who participated in the survey. The authors interviewed 26 Asian students, with the majority from China. There were two group interviews with 11 students from the Long-term group. There were then 15 individual interviews with the students from both Short-term and Long-term programs. An additional ten interviews were conducted in the US and China. Four students were in a Short-term program in a mid-Western university. The remaining six students were in a Short-term exchange 
program in Canada but had completed their studies and returned to China when they were interviewed. Interviews with these six Chinese students in China were conducted in Mandarin, and then a back-translation to English was performed.

The objectives of these interviews were to compare different forms of the data collected, gain a better understanding of the survey responses and elicit more information that was not available from the survey data. Each interview was assigned points from one to five to compare survey points for convergence and divergence: charts I and II show survey and interview data response comparisons for the Short-term and Long-term groups.

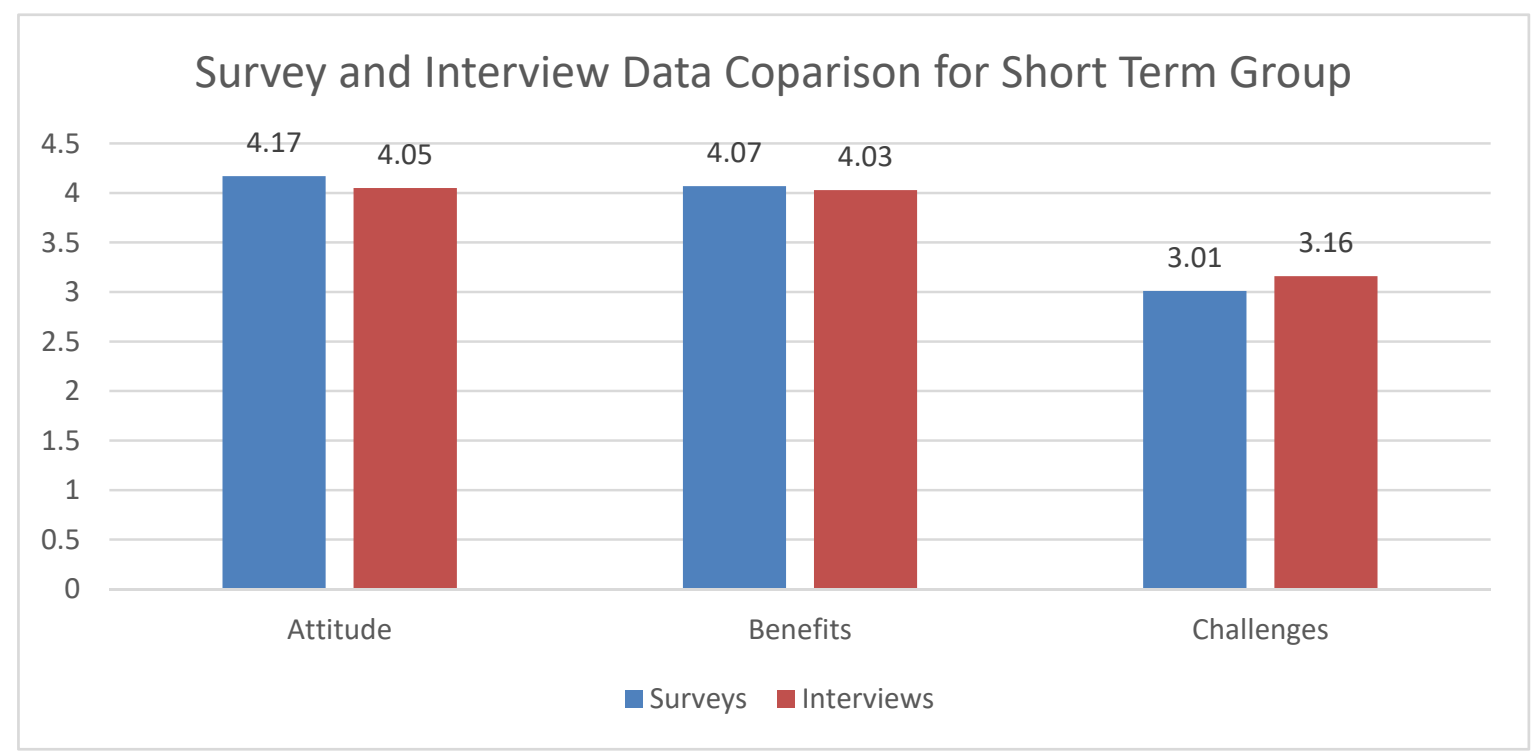

Figure 1. Survey and interview data comparison for short term group

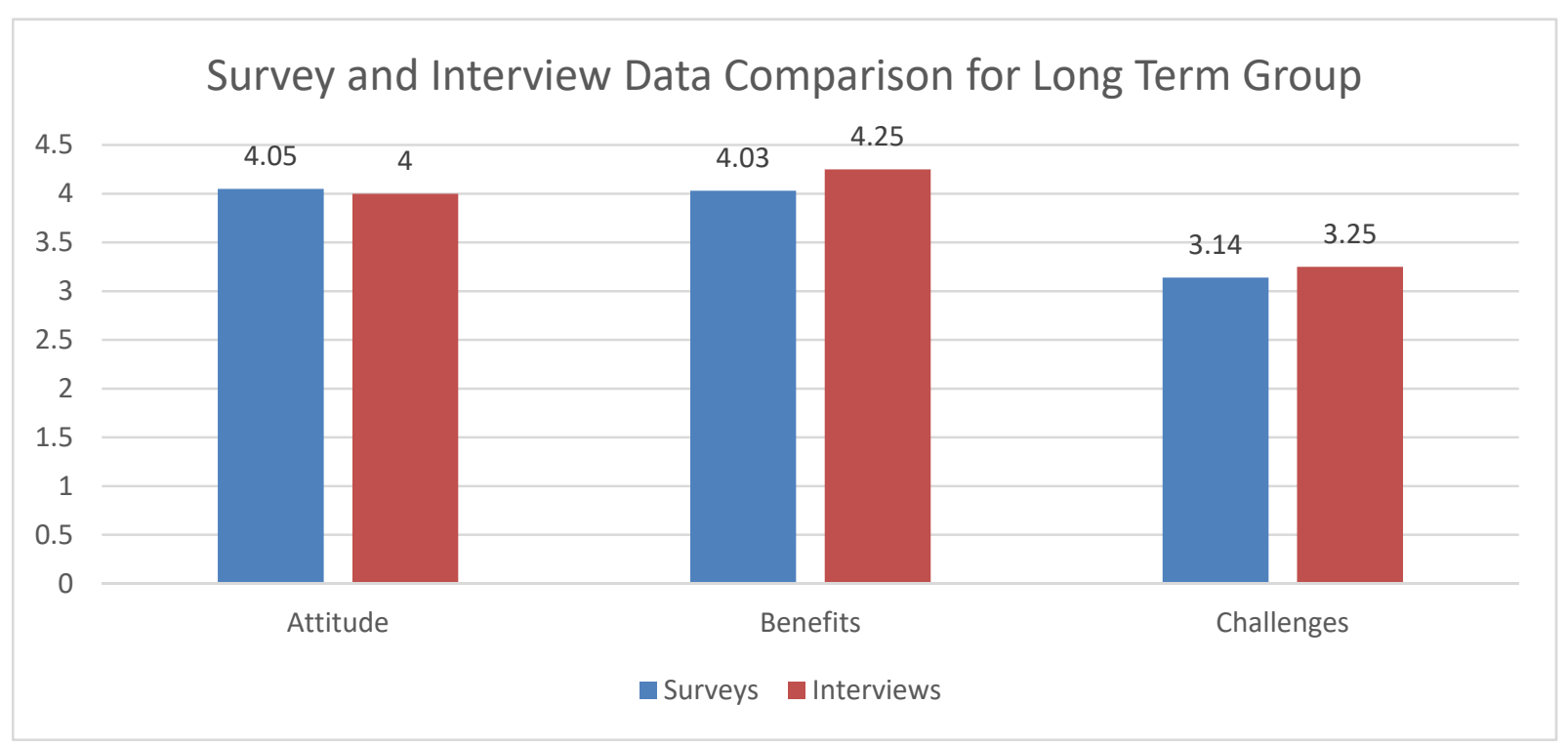

Figure 2. Survey and interview data comparison for long term group

The charts show a high level of convergence from both forms of the data collection process. This indicates that the responses from both the survey and the interviews are consistent.

Interviews Data Analysis: 


\subsubsection{The Attitude Toward EL}

Based on the survey results, the two groups have very similar attitudes toward EL, except concerning Abstract Conceptualization. The students enter international or cross-cultural education programs conditioned by their previous educational experiences. Therefore, their prior knowledge is likely to influence their attitudes. However, the Long-term group students have changed their attitudes toward EL through their study in North American institutions as they gradually accept and appreciate the EL method. The students indicated that to perform well on EL, they needed to master all learning styles rather than just some. As a result, long-term group students have positive attitudes toward EL as they highly regarded the hands-on experience. EL improved their learning outcomes and helped them connect with the real world they will step into after graduation.

Long-term student L stated: "I like more real-world examples, projects or co-operate are good ways to learn." In addition, student L indicated: "Experiential learning method helps me find a job which motivates me to study."

The students from the Short-term program still prefer a more traditional, lecture-based approach. These students' preference is driven by the learning curve to adjust to EL in light of their reasonably short time in a North American university before returning to their home country. In addition, they believe the lecture-based method is more efficient for learning theoretical knowledge, which will help them build a solid foundation for future study when they return to their home country (Students A and B).

Nevertheless, the Short-term group students expressed their motivation to keep up with the Western students by adapting to EL. One student, D, indicated that she was very motivated to adopt EL as it is the way to study in Western countries. She wants to be part of the Western students' group.

These Short-term students have modified their attitudes via their identification motive. Chinese students consider that AC may be less critical in the EL classroom. Therefore, they tried to avoid this type of learning style. Furthermore, they view the main difference between Asian and North American learning styles: the former stresses the AC approach while the latter favors the other three learning styles as more relevant to EL. This interpretation of EL could lead the students from the Short-term group to avoid EL when possible. Although Short-term students have a positive attitude toward EL, they still preferred the lecture-based teaching method.

\subsubsection{The Benefits of EL}

From the interviews, more benefits for the Long-term group in taking courses with EL were identified. These students indicated that they could have more opportunities than Short-term students to get involved in the different kinds of EL activities. This is because these Long-term program students are required to take more courses that use other EL teaching methods such as service-learning, co-op learning, project learning, and problem-based learning. Therefore, the students could get more benefit in terms of practical skills and problem-solving skills. For example, student E stated: "As a non-profit organization volunteer, I have learned the skills which cannot be obtained in a classroom setting." Furthermore, another student said: "With an experiential learning method, we can face the real problems, not just hypothetical ones. We can also observe the outcomes after implementing our recommendations," Student L. Student H added that "What works, in theory, might not work in practice, experiential learning method could help us choose and apply the appropriate theories to the real business issues."

In the interviews, 11 students from the long-term group mentioned theoretical application to the cases related to their background and past or current experiences. They reported this as the significant benefit they gained from EL. Self-education is another benefit they gained, especially students from co-op programs. It explained why Long-term students with better-designed activities that suited their learning styles using EL could achieve a higher score on active experimentation than those from the Short-term program. Nevertheless, a few students from this group indicated that they did not view EL as beneficial. This could be due to the student's involvement level in the activities or due to the activities simply not suiting some students.

During the group interviews with the seven students from the Short-term group, they expressed their appreciation of the EL method. The students indicated that improving their communication skills was the main benefit of EL projects, which often required talking with the clients and giving presentations to an audience. Student I from the Short-term group stated that EL could also increase oral communication skills via talking with fellow students, faculty members, and business owners. This skill would enable students to be better public speakers.

Students learned Western communication styles, such as assertive expression and direct response to Student J's questions. In a traditional setting, most Asian people, including Chinese, prefer indirect or ambiguous communication styles in a conversation that could be considered polite or appropriate in their home countries. 
The students $\mathrm{K}$ and $\mathrm{L}$ also mentioned that they felt uncomfortable expressing their own opinions or providing definitive answers in China. Instead, people tend to accept the views of authorities, such as experts and the leaders of organizations. After completing their EL project, the students must share and offer their own opinions with their peers to solve the problems presented.

For both groups, the students expressed that learning and enjoying the Western culture, and making new friends benefited from participating in EL projects. Although cultural differences exist, the situation has been significantly changed compared to older generations, such as Baby Boomers, Generations X or Y.

Both groups of students are from Centennials and Generation Z. Western culture is not completely foreign anymore. They can adapt to Western culture more quickly and with fewer problems than earlier generations. This was especially true in sports, entertainment, and lifestyles, including Western brands and advertisements. The students immensely enjoyed Western culture while learning something new when engaging in EL projects. In addition, the students $\mathrm{M}, \mathrm{N}$ and $\mathrm{O}$, indicated that EL could make it much easier for international students to make new friends who can provide direct assistance in their studies and daily life. The Short-term group holding EL in high regard could be due to mingling with the Western students and could be what attracted them to this new way of learning.

\subsubsection{The Challenges of EL}

Overall, both groups have lower scores and higher standard deviation levels from the survey on the questions regarding the challenges of EL. The interview data have indicated that some of the Short-term group students are still adapting to the new method, which has not been fully understood, while others have just started to realize the challenges of EL. This could be the main reason why the scores are lower and standard deviations are higher. However, the lower scores and greater standardization for the Long-term group could indicate that some students have made progress in EL, so they felt less challenged than earlier in their international education.

Other students in this group may still feel challenged after a couple of years of study with EL. These students with lower scores identified themselves as passive learners who did not take the lead in group work. This could be another factor for these students in deeming EL more challenging. During the interviews, some of the Long-term students expressed such concerns. This interview data justified why the students' survey numbers varied significantly, i.e., some students rated these questions with " 1 ". In contrast, others rated them with "5" as the students had completely different views on the challenges of EL.

Through the interviews, the authors also found other types of challenges, as discussed below. Lack of communication training was the main challenge for both groups. Sometimes, the students assumed that the weaker adaptability to EL was due to a lack of English-speaking skills. This could certainly be a factor but was not the only reason for this situation. The authors observed that educators often underestimate the capability of communication while overestimating language ability. Both Chinese students and some foreign instructors believed that if only students had a good command of English, they could perform like Western students. Therefore, a lot of time and energy improves English language skills while ignoring cultural orientation and communication skills. Students P and Q indicated that they had very high English oral and written exams but still felt uncomfortable talking with English-speaking people, especially in public settings. The real challenge of doing well in EL is communication skills, rather than purely understanding English. The surveyed students previously indicated that the significant improvement in their communication skills was learned from EL activities through presentations, group discussions, self-evaluations, or reflection activities, distinct from lecture-based teaching methods.

Cultural factors can also alter or affect the communication styles, which could inhibit the students from achieving a better performance in EL activities. For example, a student from the US said: "In Korea, when you do not talk, other students would invite you to discuss and have a conversation. Here, with the individualistic culture, you need to initiate the talk and not be invited for talks."

Student H said: "Local students sometimes were not patient to listen to our ideas in group work; they are always talking without offering us the opportunity to express our opinion." This could be due to cultural conflicts or personality differences. International students will have to face such challenges if they get involved with EL activities.

The authors observed that Asian students are quieter in their classes or indirect in expressing their opinions relative to their North American counterparts. This could also be related to their communication abilities, social norms, and personalities. They prefer to be invited to talk and share their opinions in public and avoid conflict. That is why a student in the Short-term group perceived the local students as impatient, but they did not want to 
point that out in the classroom. Cultural differences lead to some misunderstandings between and among team members.

\section{Lack of Work Experience in North America or Home Countries:}

A lack of work experience or professional training is another challenge for both groups. The students commented that they felt intimidated and uncertain about facing situations they had never experienced. Student R, attending school in the US, said: "the project could be intimidating, as I had no experience before." Finding a good solution for a local business could be challenging as we have not had any related professional training," Student $\mathrm{S}$ from the Long-term group.

In North America, most students have had some kind of work or volunteer experience before entering and during their college years. Therefore, these students have the advantage in solving problems encountered during the EL projects. However, Asian students, mainly Chinese students, are unlikely to have work experiences before their college years and even less likely to have any Western work experiences. This is a cultural difference between Western countries and China even today. Chinese parents would not usually allow their children to work before they are admitted into universities. Under traditional teaching methods, this may not be an issue for the students as the lecture-based method does not require the skills required for EL, which encourages students to learn by doing. Although it could be a challenge for the Asian students without work experience when involved in an EL project, they will eventually overcome this challenge and gain the necessary skills by doing the EL projects.

A Lack of Connection Between Academic Goals and Experiential Learning Objectives:

A significant challenge for Short-term group students is that they could not link their own academic goals to the EL objectives. Short-term group students have a clear educational plan to pursue an advanced degree in their home country, for example, China. The students perceived that EL activities do not positively affect their exam grades, which will be the only criterion for entering post-graduate programs in China. The students from the Short-term group also felt EL projects are unproductive as they are very time-consuming. According to a student from the Short-term group attending a university in the US, only quizzes and exams are essential for their immediate academic goals. However, factual evidence showed that many Asian students achieved high grades in their final exams. A large mega study argues that EL stresses the importance between learning sessions and involved modes of abstractive conceptualization, which is closely related to lecture-based pedagogy and can benefit students in the long run (Burch et al., 2016). Another major study by Specht \& Sandlin (1991) stated that EL could help students retain their learning results better than the lecture-based method. The study documents that the exam scores are the same for both types of student experiences, but the student exam scores from the EL group stay the same while the other students' exam scores decreased after six weeks (Specht \& Sandlin).

\subsubsection{Preferred Pedagogical Practices for EL}

This study has identified several preferred pedagogical practices for EL. These pedagogical practices can apply to both groups of students as both shared significant similarities. However, the differences exist, which indicates that the Short-term group students need additional measures of support.

\section{Develop Well-Balanced Learning Styles:}

The instant study showed that both groups had faced challenges, but the levels and types of challenges differed. The students from a Short-term program could not describe the specific challenges the students had or will have. Alternatively, in some cases, they do not know the challenges as they are still being introduced to EL. The students in this group assume EL favors the AE rather than AC. They adapt to their participation in EL projects by avoiding the AC learning style to be similar to their North American peers. This approach may not be appropriate as many learning styles can be applied to EL. No single learning style is better than another. As Kolb points out, educators should not rank learning styles but rather utilize a well-balanced learning approach in adopting EL pedagogy (Kolb, A. Y. 2005). The instructor should emphasize the importance of the four learning styles in the project design rather than just the AE aspect. EL pedagogy does stress learning by doing, but this "active experimentation" must be guided by theories driven by Abstract Conceptualization. Learning from experience is different from a pure experience because the experience itself is not enough for productive learning outcomes.

\section{Design the Teaching Methods Focusing on Students' Past and Indirect Experience:}

Giving attention to the students' experience is critical for the EL process. According to the cognitive constructivist theories of Piaget (1985) and Vygotsky (1978), people construct new knowledge and understanding from what they already know and believe, based on their previous experience. In other words, when the situation is in context, students can learn most effectively. Therefore, instructors need to understand 
and pay attention to students' past relevant experiences to integrate their experience into a new learning environment. Therefore, previous experience is essential in EL. Some international students will encounter more difficulties in situations they have not faced before, or have conflicts with their cultural background, so they should be prepared with more background knowledge. The more equipped with such knowledge, the more benefit they will get from EL.

Based on the instant study, the Long-term group students gained significant experiences through EL activities, and they could relate these experiences to their learning. As a result, Long-term students may have more opportunities to gain benefits than Short-term students. However, it is critical to point out that EL itself does not generate the full benefit of this learning opportunity for international students. If both well-designed activities that fit the students' backgrounds and their learning styles are considered, can students achieve the maximum benefits from EL activities? A major study showed a similar assertion that the fitness of the projects to the students matters more than their desired learning outcomes (Burch et al., 2016).

Be Aware of Educational Culture-Related Communication Factors in Teaching:

Although cultural convergence occurs, divergence still exists. Especially, educational culture-related communication factors could affect the overall communication success or failure. Academic culture-related communication is most relevant to the learning and teaching environment. From the interview results, cultural conflicts led to misunderstandings between learners and instructors during the class session. For example, a student from an Asian country viewed his instructor as inconsiderate when he failed the course only for not having citations in his paper, which was not common in his country. According to Trompenaars' (1993) work, Riding the Waves of Culture, people's expression of emotion from certain cultures is held in check. People's feelings are openly and naturally expressed in other cultures. The outcome of the present study indicated that students from Asian countries mentioned that their western peers were arrogant because they did not listen patiently to them, which is regarded as rude in their culture. Some Asian students would like to be invited to speak or share their ideas instead of taking the initiative to talk in public, which Western students take for granted. Lack of ability to express ideas also comes from other cultural factors, such as "power distance." Chinese students prefer to accept the opinions of authorities. Their way of learning exposes them to lecture-based learning from early education to later stages of education in which oral communication, critical thinking, and hands-on experience are deemphasized. Therefore, the implication of common practice or rules in EL should be illustrated clearly by teachers in the initiation process, such as self-built knowledge. Critical thinking and expression training should be emphasized in Chinese education.

This study reveals that providing more opportunities for Short-term students to get involved in service-learning, especially connecting a service-learning project to community-based participatory research ("CBPR"), can be beneficial. This involves students and faculty working collaboratively with community partners to resolve problems closely related to community needs. At the same time, instructors should develop some critical tasks for international students who can complete EL projects by utilizing their past and current experience and knowledge from a unique cultural angle. In doing so, the students from a Short-term group can gain first-hand experience during their learning activities. Furthermore, this direct contact with the real world enables the student to advance their knowledge in a shorter period.

\section{Conclusion}

This study has identified the international students' attitudes and their benefits and challenges for EL pedagogical practices. These students, mainly Asian students studying in North American institutions, were the main subjects of this study. The data collected from both forms of analysis in this study, quantitative and qualitative, are convergent in general; hence, some detailed elaborations gained from interviews enriched the overall data.

The study found that Asian students hold a positive attitude toward EL pedagogy, allowing educators to explore this new way to learn. The study also identified the benefits that international students could receive through EL educational activities, encouraging the students to improve the learning process in North American countries.

However, EL is new to most Asian students who have not been exposed to this pedagogical approach in their home countries. Thus, it is challenging for Asian students to adapt to this new approach. Previous studies showed that students grow best where they continuously experience a blend of challenge and support (Kegan, 1994). Therefore, educators need to develop relevant EL activities based on Asian students' learning preferences. It is also critical for the universities to identify, modify and justify appropriate learning environments which could fundamentally enhance international students' learning capabilities and enrich their learning outcomes.

This study has revealed some recommended implementation methods for both Long-term and Short-term groups 
of students from Asia. The first step of the implementation process is acknowledging that all learning styles are equally good when the appropriate learning environment is identified. In addition, educators should emphasize that no one learning method is superior to another. The second step aims to incorporate an approach to include the four EL learning styles developed by Kolb into the Asian students' new EL learning method. The third step is balancing these four learning styles then linking these styles to an appropriate learning environment that could reinforce learning effectiveness. Together, the successful implementation of these steps could also make it easier for educators to assist Asian students' transition from lecture-based to experiential learning-based learning styles.

While the implementation strategies are intended for Asian students, many of these strategies can be applicable for non-Asian international students who have shared similar characteristics, such as studying the same subject and residing in the same host countries for an equivalent length of time. In addition, the students accustomed to a lecture-based, traditional pedagogy in their home countries can benefit from EL pedagogy.

This study has several theoretical and practical implications. First, the positive attitude from international students can provide a solid foundation for North American universities to adopt EL in diverse learning environments. Second, the benefits identified could motivate international students to adapt to EL methods. Third, the challenges and corresponding suggestions or solutions may also be relevant to North American students who may need to adapt their learning styles into a more internationalized setting where new perceptions, ideas, and innovative approaches from other cultures and countries emerge. Finally, educators and administrators could also help international and domestic students become members of their new community by adjusting to this new learning environment, which is much different from their home countries.

The limitations of this study are worth noting. First, the research data were collected based on volunteers; therefore, selection bias may exist. Second, survey data were collected from a single school within an institution, construed as fairly limited coverage. Third, the comparison between the two forms of data may miss the divergence in certain themes and concepts while a follow-up investigation was not performed. Finally, due to the ability of researchers, it is possible that some information was not adequately detected during the study.

Applying the results of this study to students in other countries, such as Africa, the Middle East, and South America, could be an excellent opportunity for future research. The research results support the notion that EL could be a strategic alternative for international business education, even though the traditional approach, such as the lecture-based teaching method, is still prevalent in many countries. The study suggests EL could be an excellent addition to the traditional system, but it is not replacing it.

\section{References}

Azriel, J. A., Erthal, M. J., \& Starr, E. (2005). Answers, questions, and deceptions: What is the role of games in business education? Journal of Education for Business, 81(1), 9-13. https://doi.org/10.3200/JOEB.81.1.9-14

Batalova, J., \& Zong, J. (2016). Language diversity and English proficiency in the United States. MPI: Migration Policy Institute. Retrieved from https://www.migrationpolicy.org/article/language-diversity-and-english-proficiencyunited-states

Burch, G., Giambatista, R. C., Batchelor, J., Hoover, J. D., Burch, J., Heller, N., \& Shaw, J. (2016). Do experiential learning pedagogies affect student learning? A meta-analysis of 40 years of research. Academy of Management Proceedings, 1(1), 1672-1677. https://doi.org/10.5465/ambpp.2016.127

Canadian Bureau for International Education. (2018). International students in Canada. Retrieved from https://cbie.ca/infographic/

Chen, R. T. H. (2014). East-Asian teaching practices through the eyes of Western learners. Teaching in higher education, 19(1), 26-37. https://doi.org/10.1080/13562517.2013.827652

Creswell, J. W. (2014). A concise introduction to mixed methods research. SAGE publications.

Dewey, J. (1986, September). Experience and education. The Educational Forum, 50(3), 241-252. https://doi.org/10.1080/00131728609335764

Getie, A. S. (2020). Factors affecting the attitudes of students towards learning English as a foreign language. Teacher Education \& Development, 7(1), 1-32. https://doi.org/10.1080/2331186X.2020.1738184

Hickcox, E. S. (1991). The Recruitment and Selection of Directors of Education: An Ontario Example. Education Canada, 31(1), 22-26.

Iliff, C. H. (1994). Kolb learning style inventory: A meta-analysis.

Kegan, R. (1994). In over our heads: The mental demands of modern life. Harvard University Press. 
Kolb, A. Y. (2005). The Kolb learning style inventory-version 3.12005 technical specifications. Boston, MA: Hay Resource Direct.

Kolb, D. A. (1984). Experience as the source of learning and development. Upper Saddle River: Prentice-Hall.

Levsen, V. B., Goettel, N., Chong, F., \& Farris, R. (2001). Do we practice diversity in business schools? International Journal of Educational Management. https://doi.org/10.1108/09513540110394401

Matsuo, M., \& Nagata, N. (2020). A revised model of experiential learning with a debriefing checklist. International Journal of Training and Development, 24(3), 144-154. https://doi.org/10.1111/ijtd.12177

Miller, R. J., \& Maellaro, R. (2016). Getting to the root of the problem in experiential learning: using problem solving and collective reflection to improve learning outcomes. Journal of Management Education, 40(2), 170-193. https://doi.org/10.1177/1052562915623822

Okoli, J., Nuno, A., \& Barish, O. (2019). Piloting a Portfolio of Experiential Learning Activities for International Business Students. Journal of Teaching in International Business, 30(3), 219-245. https://doi.org/10.1080/08975930.2019.1698393

Piaget, J. (1985). Equilibration of cognitive structures. University of Chicago Press.

Piercy, N., \& Caldwell, N. (2011). Experimental learning in international classroom: Supporting learning effectiveness and integration. The international journal of management education, 9(2), 25-35. https://doi.org/10.3794/ijme.92.313

Schein, D. D., \& Song, W. (2016). Teaching marketing ethics: A preliminary study. International Journal of Teaching and Case Studies, 7(1), 82-98. https://doi.org/10.1504/IJTCS.2016.076068

Schelbe, L., Petracchi, H. E., \& Weaver, A. (2014). Benefits and challenges of service-learning in baccalaureate social work programs. Journal of Teaching in Social Work, 34(5), 480-495. https://doi.org/10.1080/08841233.2014.954689

Schenck, J., \& Cruickshank, J. (2015). Evolving Kolb: Experiential education in the age of neuroscience. Journal of Experiential Education, 38(1), 73-95. https://doi.org/10.1177/1053825914547153

Seaman, J., Brown, M., \& Quay, J. (2017). The evolution of experiential learning theory: Tracing lines of research in the JEE. Journal of Experiential Education, 40(4), NP1-NP21. https://doi.org/10.1177/1053825916689268

Specht, L. B., \& Sandlin, P. K. (1991). The differential effects of experiential learning activities and traditional lecture classes in accounting. Simulation \& Gaming, 22(2), 196-210. https://doi.org/10.1177/1046878191222003

Trompenaars, F. (1993). Aiding the waves of culture: Understanding diversity in global business. Homewood, IL: Irwin.

Vince, R. (1998). Behind and beyond Kolb's learning cycle. Journal of Management Education, 22(3), 304-319.

Vygotsky, L. (1978). Mind in Society. London: Harvard University Press.

Zong, J., \& Batalova, J. (2018). Spotlight: International students in the United States. Migration Policy Institute. Retrieved from https://www.migrationpolicy.org/article/international-students-united-states

\section{Note}

Note 1. Funding Number: YB17-32, title "The research on TUT-TRU joint teaching program" sponsored by the Teaching funding of Tianjin University of Technology.

\section{Copyrights}

Copyright for this article is retained by the author(s), with first publication rights granted to the journal.

This is an open-access article distributed under the terms and conditions of the Creative Commons Attribution license (http://creativecommons.org/licenses/by/4.0/). 